\title{
From Subculture to a Means of Social Inclusion: Transnationalism and Skateboarding Culture in Amman, Jordan
}

\author{
Jakub Novotný*
}

University of West Bohemia, Czech Republic

\begin{abstract}
The paper represents an ethnographic study of a skateboarding community in Amman, Jordan. My aim is to explore how participation in skateboarding influenced identity construction of the community members and their relationships with a broader social milieu they lived in. I explore the social composition of Amman's skate scene, as well as issues of inclusion and social diversity. Subsequently, I seek to find out how transnational ties of Amman's skaters and interaction with their foreign counterparts influenced the development of Amman's skate scene. The paper is based on data collected through ethnographic fieldwork in Amman between September and December 2014 and subsequently in August 2018. Firstly, the fieldwork consisted of participant observation at skateboarding locations. Secondly, it included semi-structured interviews with a total of fifteen respondents Jordanian skaters and foreigners involved in skateboarding projects in Amman - while ten more interviews were conducted via communication platforms such as Messenger and Skype. I also analyzed the content of relevant websites and social media platforms. The study shows the Amman's skate community as a subculture that revolved around appropriating places in the urban space. I explain that skateboarding in the Jordanian capital prior to 2014 was an activity confined to relatively privileged youth, since participation required economic and social capital indispensable to gain access to skateboarding equipment. Positioning Amman's skate community in a global context, I show that the skaters' transnational ties, related primarily to their family backgrounds, were also expanded through participation in skateboarding. Namely, I show the role of Philadelphia Skateboards - the first skateboarding brand in the Arab World - in stimulating active interaction between Amman's skaters and their foreign counterparts. In the last chapter, I focus on the circumstances of 7 Hills Skateparks project. I explain a broader context of skateboarding within ASDP movement (Action Sports for Peace and Development) and the policies of Make Life Skate Life - the organisation which carried out the project. I also demonstrate how the project exposed skateboarding to new participants and transformed skateboarding from a subcultural practice pursued by a group of Westernised youth into a tool for social inclusion.
\end{abstract}

\section{Keywords}

skateboarding, Jordan, Middle East, youth culture, subculture, transnationalism, social inclusion

\footnotetext{
* Corresponding Author: Jakub Novotný, Department of Anthropology, Faculty of Arts, University of West Bohemia, Sedláčkova 15, 30100 Plzeň. E-mail: jakub.ntl.novotny@gmail.com.
} 


\section{Introduction}

Amid the accelerating process of globalisation and transnational mobilities, youth across the world have been increasingly exposed to Western cultures and lifestyles. As Kehily and Nayak write, "[a] commonly held view suggests that globalisation in the cultural sphere produces Western hegemonic structures at the expense of local cultures. Cultural globalisation has been characterised as the flow of ideas, products and practices from the Western 'core' to the 'periphery' of non-Western locations" (Kehily, Nayak 2008: 328). While such view highlights the process of "McDonaldization" (Ritzer 1983) of consumption patterns, it does not reflect the complexity of various creative forms of cultural appropriation by youth on the "periphery". Although "[...] the global eclipses the local" in youth cultures (Nilan, Feixa 2006: 3), the process of cultural globalisation does not produce a homogenous mass of consumption-oriented youth. Rather, it leads to hybridisation of cultural forms and emergence of plural worlds wherein the youth subjectivity is constituted "[...] within a number of salient discourses" (Nilan, Feixa 2006: 3).

In this paper, my objective is to show the relationship between local and global aspects of a youth culture existing on the "periphery", by presenting a case study of a skateboarding community in Amman, Jordan. In the first part, I explain how the group of skaters creatively used urban architecture and adapted their practice to local physical space. Drawing on the notion that "[y] outh cultures are always emphatically local $[. .$.$] since youth are embedded in immediate$ and embodied economic and political relations" (Nilan, Feixa 2006: 8), I further elaborate on the relation between skaters' spatial practice and public attitudes towards their presence in the city. Showing that the skaters identified their practice as a constituent of a complex lifestyle that differentiated them from the majority, my aim is to explain the multi-faceted and contextual relations between the skateboarders and the broader social milieu they lived in.

Positioning the community in a broader social context then opens up a space for discussing the socioeconomic, religious and ethnic backgrounds of the skaters and showing how their ascribed status influenced identity construction within their group. While showing the role of social status in the formation of Amman's skateboarding community, I subsequently focus more closely on how this group of youth experienced and engaged in different forms of transnationalism. First, I explore transnationalism as understood in the context of international labor migration - i.e. chiefly "[...] the processes by which immigrants build social fields that link together their country of origin and country of settlement" (Schiller, Basch, Blanc-Szanton 1992: 1). I show how international migration of the skateboarders themselves, their relatives and close friends and presence of expatriate youth in Amman influenced the development of the local skateboarding community. Secondly, I explore the context of "[...] transnational flows and networks in contemporary youthdominated action sports cultures" (Thorpe, Ahmad 2015: 679). I focus on projects that either were initiated by members of the community or directly involved Amman's skaters. Namely, I discuss the role of Philadelphia Skateboards, one of the first skateboarding brands in the Arab world, in establishing new and expanding existing transnational ties between Amman's skateboarding scene and skaters from other parts of the MENA region and the West. Subsequently, I elaborate on 7Hills Skatepark, a project conducted by organisation Make Life Skate Life (MLSL), which was set to provide a designated skateboarding space for underprivileged youth, while engaging the existing skating community in Amman. I offer a critical insight into the circumstances of the project's realisation and, more broadly, important aspects that shape the NGO's policies. I also discuss subsequent 7Hills project formed in 2016, which stimulated a transformation of skateboarding in Amman from a subcultural practice pursued by a group Westernised youth to a tool for organised social inclusion.

The paper is based primarily on ethnographic data collected in Amman between September and December 2014 and subsequently in August 2017. The fieldwork consisted of participant 
observation and interviewing Amman's skaters as well as foreigners involved in skateboarding projects in the Jordanian capital. I also interviewed several Jordanian skaters via platforms such as Skype and Messenger, since some of them resided outside of the country at the time of my fieldwork. Several interviews with responsible individuals were also conducted between 2015 and 2018 in order to gain information about the development of the 7Hills Skatepark project.

\section{Skate Scene in Amman: A Distinct Urban Subculture?}

As political, economic and social structure of Western societies evolved during the second half of the twentieth century, so did the meanings and definitions of subculture as a theoretical concept in social science. In the 1970s, scholars such as Dick Hebdige or Stuart Hall from the Centre for Contemporary Cultural Studies (CCCS) described subcultures as a symbolic response of underprivileged working class youth to capitalist social order (Hebdige 1979; Hall, Jefferson 1976). Yet, in the early 1990s, the paradigm of subcultural theory shifted towards a stance that resisted the notion of subcultures as primarily class-based phenomena. Whereas Hebdige's punks were working class youth pointing a middle finger at the establishment (Hebdige 1979), Thornton's ravers were young males and females who did not care so much about rejecting capitalism but sought to differentiate themselves from the mainstream in their quest for subcultural capital (Thornton 1995). Thornton's perspective emphasising the tastes and deliberate choices of youth on one hand and the class-based explanation of CCCS scholars on the other can be viewed as two poles that have guided subsequent developments of the subcultural and post-subcultural theory. From abandoning the term subculture in favour of concepts such as neo-tribe that supposedly suited better the fluid and arbitrary participation of youth sub-cultural formations (Bennet 1999), to reviving the emphasis on class formulated by Birmingham scholars (Jensen 2018), the paradigmatic debate is ongoing and provides us with a wide array of possible theoretical frameworks. Where should we look then, if we attempt to study an originally Western youth culture, appropriated in a non-Western geographical and cultural context? The recent anthology Arab Subcultures (Sabry, Ftouni 2017) provides a valuable source of ideas for such research. The majority of texts in the edited volume deal with youth cultures whose adherents often face prosecution either from their conservative social milieus or authoritarian regimes (i.e. queer communities, political activists). Even though positioning skateboarding among such subversive movements or youth cultures clearly at odds with conservative social and cultural norms would be misleading, the work of scholars researching Arab subcultures shows us the radically different conditions we cope with when applying Western understandings of subculture to the context of predominantly Arab societies. With a more holistic take on urban youth cultures in Egyptian context, Heba El Sayed provides particularly useful thoughts for the subject of this paper. Her emphasis on class as a primary determinant in cultural choices of young males and females resonates with this study, as I will later show (El Sayed 2017).

Informed by the subcultural theory and its appropriation for the specific contexts of both Arab societies and skateboarding as a distinct culture, the following chapter gives us space to look at the origins of Amman's skate community and discuss the conditions (mainly appropriation of urban space) and subjectivities (i.e. positioning oneself vis-á-vis the dominant culture) that shaped its development. Subsequently, I will discuss Amman's skate scene in a broader social context, focusing on the backgrounds of its members and elaborate on issues of social status.

Since the late 1980s and early 1990s, skateboarding in a global context has developed from "[...] an outsider subcultural activity", considered "[...] at best a nuisance, at worst a crime" to a "sporting activity where to skateboard meant to practice, to be coached and ultimately to have [...] a shot at making big money as a professional athlete" (Lorr 2016: 138, 139). However, 
as Dupont argues, while the activity has been increasingly commercialised and institutionalised, the "[...] values created during the late 1980 s continue to remain dominant within skateboarding and strongly influence the ideologies, lifestyle, and hierarchy of skateboarding at the local level" (Dupont 2014: 562). Amman's skaters largely identified with the subcultural, outsider ethos of skateboarding as they followed media outlets such as Thrasher Magazine that portrays the culture as edgy and rebellious, using the renown quote "Skate and destroy" as its slogan. Yet, more importantly, the collective identity of Amman's skaters was constructed through their daily experience as a marginal group pursuing an activity they deemed as alien to the broader social environment.

In the Jordanian capital, the inception of what can be labelled as a skate scene dates back to 2002 when Mohammed Zakaria started meeting his friends for regular sessions in Amman's Shmeisani neighbourhood. Prior to that, Zakaria owned a skateboard but as he recalled, he only used it as a toy and was not aware that it was possible to perform sophisticated manoeuvres on it. It was only when he first gained regular access to the internet that he learned about professional skateboarding and possibilities the activity offered in terms of self-development. Likewise, going online helped Zakaria discover peers who shared his newly found passion. Using a skate-related nickname, Zakaria established links with other Amman skateboarding enthusiasts on chat forums and subsequently started meeting them on a regular basis (Zakaria 2014c). Thus, skateboarding started to develop in Jordan as a youth culture that emerged in the country due to the internet, whose proliferation allowed for dissemination of Western cultural influences. Yet, while the young of Amman's skaters drew ideas and inspiration from online sources, the actual physical space of the city was essential for the very practice around which the skate community formed. As purpose-built areas for skateboarding were absent in the Jordanian capital well until 2014, skaters appropriated places in the city. This reified their self-perception as a non-conformist group creating its own logic and rules of using urban space. The history of skateboarding community in the Jordanian capital is closely connected with a space known as Culture Street or, in Arabic, as Share'eth Thaqafeh. The spacious boulevard in Shmeisani's commercial district was built in 2002 when Amman was declared the Arab Capital of Culture. Shortly after, it became the central site for an emerging community of skateboarders, mainly because its architectural features such as smooth basalt and granite floor or ledges of different shapes and sizes were perfectly suitable for their activity. As Borden writes "[...] it is sometimes argued that the most effectively appropriated spaces are those occupied by symbols (Borden 2001: 5). Culture Street was indeed replete with symbolism, designed as a presentable landmark of a city celebrating its newly acquired prestigious title, a bustling boulevard that would become the heart of new Amman. The symbolism ascribed to Culture Street by the policymakers was re-appropriated by Amman's skateboarders. As one of them, Ahmad Sahli wrote it in his article Skating For Self-Expression: "[...] there's something special about it that gives it a reason to be called Culture street" and that "[...] to some it may be overlooked as just another business area but to Ammanis it means much more" (Sahli 2010). The skaters would often highlight the importance of Culture Street as the location "where it all started", portraying it as a space that was crucial for the emergence of Amman's skate community.

During the time of my fieldwork, I observed that passers-by reacted rather positively to the presence of skateboarding at Share'eth Thaqafeh. It was not uncommon that families with preschool age children stopped to watch skaters performing tricks and admire their skills. Multiple times, parents even encouraged their children to ask the skaters to lend them their skateboards so that they could try the activity themselves. Yet while the skateboarders admitted that friendly public reactions to their presence were not rare, they emphasised that negative ones occurred regularly as well. Likewise, since skateboarding at Share'eth Thaqafeh had never been officially 
permitted, the skaters occasionally ran into clashes with agents of law enforcement. Several times, the police attempted to prevent them from riding at the location. One such event was reflected on Skatejordan.blogspot.com: "Last night (July 1, 2008) several skateboarders in Shari3 Thaqafeh were taken down to the police station. Why? I'm not sure what provoked this action. They had to each sign a paper that they will not skate in Shari3 Thaqafeh and if they did so they would have to pay 1000JD fine" (Sahli 2008).

Even though confrontation with police was not a regular occurrence at Share'eth Thaqafeh, it reified the skaters' self-ascribed outsider status. Similarly, members of the skate community noted that their activity was perceived as a Western cultural import and sometimes even associated with Satanism. "It seems every new form of self-expression in Jordan has to be met by society with an accusation of SATANISM. In the 1990's it was heavy metal and the kids with black T-shirts. Now the skateboarders? DUH!" (360 East 2007). While the skaters admitted that such form of rejection was rather extreme, they sometimes noted that their activity was usually looked upon as a futile childish pastime. Such view was commonly expressed by their family members who discouraged them from pursuing the activity. As Tamer said, his friends were pressured to quit skateboarding and focus on "meaningful" goals in life, such as marriage or professional career (Tamer 2014). Facing family pressure and public disdain were described by most skaters as integral parts of their collective experience. Being aware of their marginal status, they sometimes expressed desire that skateboarding be recognized as a socially beneficial activity. As Ahmad Sahli wrote on Skate Jordan: "We have adopted a physically active lifestyle that is so very valued by the government (as seen in ad campaigns and so on). It's our job to present skateboarding as a sport just like any other" (Sahli 2008).

Even though the skaters thought public acceptance was important for the development of their activity, they did not agree on the ways in which such acceptance should be improved. The excerpt above is from a discussion that appeared on Skate Jordan blog when the presence of skateboarding at Share'eth Thaqafeh was threatened by police interventions. It shows a rather conforming stance as most Amman's skaters expressed an opinion that the society just "should get used to skateboarding" and thought of their practice as inherently non-conformist. However, according to Mohammed, the understanding of non-conformity among the skaters was radically different from that of the public. The public disdain for skateboarding was seen as a result of incomprehension and ignorance that equated non-conformity with vandalism and nuisance (Zakaria 2014c). On the other hand, Amman's skaters primarily saw their non-conformity in pursuing an unconventional, creative activity that differentiated them from a "uniform mass". Such view reflected Beal and Weidman's observation made during their ethnographic fieldwork among skaters in a US city. The authors write that the participants valued non-conformity more "[..] if it was seen as a creative means of self-expression, and valued it less if it was simply an unreflective rebellious act" (Beal, Weidman 2003: 342). Likewise, Amman's skaters deemed creative self-expression as an essential characteristic of the skate culture and sometimes compared their activity to art. The main reason why they pursued skateboarding was to explore new ways of creatively using urban terrain and develop a unique, individual style. As Tamer noted, skateboarding gave him a sense of freedom because it did not have an organised structure: "When you skate, you can go out for a session whenever you want. You don't have to listen to a coach who tells you what to do" (Tamer 2014). By the same token, some of Amman's skaters explained how discovering skate culture sparked their interest in other creative and artistic activities. Misha and Tamer, influenced by soundtracks of US skateboarding videos, grew profound interest in music and they both became active musicians. Tamer played drums in a heavy metal band, whereas Misha was a guitarist in a punk formation. For Mohammed and Hamzeh, interest in skateboarding videos and magazines was a reason to learn about filmmaking and photography, and both subsequently developed careers 
in the respective fields. As Mohammed explained, "[...] stepping into the uncertain realm of freelance work" was a result of "[...] independent, non-conformist way of thinking" he developed through skateboarding (Zakaria 2014c).

For majority of Amman's skaters, adherence to skate culture formed an important part of their identities. As Mohammed, Misha and Tamer explained, skateboarding deeply influenced various aspects of their lives that were not directly related to the activity. From the style of clothing or music preferences to the way they perceived the urban environment, participation in skateboarding constituted a complex worldview and lifestyle. How did the self-identification of skaters as adherents to a distinct culture, then, influence the boundary construction of their community?

\section{A Diverse Community? Social Backgrounds of Amman's Skaters}

In the last two decades, one of the common themes addressed by scholars interested in skateboarding culture has been the issue of inclusivity and social diversity. Borden explains how skateboarding in the US developed from a culture dominated by white middle-class males to a more racially heterogeneous one during the 1990's (Borden 2001: 141). The change occurred when skateboarding gradually moved from suburbs to centres of big cities and youth from diverse social and ethnical backgrounds were exposed to the activity. "Consequently, there have been little or no racial tensions in skateboarding" (Borden 2001: 141). Such view is reflected in some accounts of personal experience with involvement in skateboarding culture. For instance, as Castaneda described in his essay Kick Flipped: How Skateboarding rides with race: "It wasn't until many years later that I truly began to realise just how unique, and perhaps unlikely, our friendships were. While some lived in the quiet and affluent communities of Coronado or North San Diego County, others crossed the border from Tijuana, Mexico every day to skate. Through skateboarding, I was not only able to stretch the horizons of my physical world but my social sphere as well. I had friends from all backgrounds, both ethnic and socio-economic, and it never occurred to us that our mixed group was uncommon outside of skateboarding" (Castaneda 2008). Nevertheless, the portrayal of skateboarding as inclusive and open to diversity has also been challenged in some scholarly works, especially by researchers who focused on females' role in the culture. While most recent trends show that women's active participation in skateboarding becomes widespread and normalised (Atencio et al. 2018), female participants have long occupied a " [...] subcultural edgeland position" (Abulhawa 2008: 59). As Beal wrote in 2003, females who skated "[...] were often perceived as groupies and [...] not taken as seriously as males" (Beal, Weidman 2003: 345).

However, it is not solely through addressing inter-gender relations that the notion of equality becomes problematic. In a study focused on the informal hierarchy of skateboarding culture, Dupont claims that inequalities based on race play a significant role in its shaping as well. The author notes that "[...] skaters have access to freedoms that are unequally divided along race lines" (Dupont 2014: 570). Citing Brayton, he shows that some key components forming the skaters' identities, such as travel, were "[...] tacitly reserved for white middle-class males" (Brayton, cited in Dupont 2014: 570). Yochim notes that "[...] skateboarders frequently translate their outsider status into assertions of cultural acceptance" (Yochim 2009: 99). Nevertheless, she further explains that the group of skaters she studied "[...] saw no need to make a conscious effort to include frequently excluded groups" and that "[...] whiteness and masculinity remained the unstated norms, a status that cultural theorists have demonstrated to be a position of power" (Yochim 2009: 105). Yochim's theorization thus shows that equality and inclusion in skate culture are more often "imagined", rather than practiced. Even though her assertion was formulated through empirical findings in the US, the notion of difference between "imagined" and actual equality is relevant 
for the context of this study as well. As I will demonstrate, members of the skate community thought of themselves as a group that welcomed diversity, but the participation in skateboarding was related to a relatively privileged social status.

Regarding its socio-ethnic and confessional composition, Jordanian society can be characterised as rather heterogeneous. Throughout the second half of the twentieth century, the Arab-Israeli conflict caused an exodus of Palestinians who subsequently outnumbered the indigenous Jordanian population, formed predominantly by sedentary Bedouin tribes (Zahran 2012). Besides Palestinians, Circassians, an ethnic group that migrated from Caucasus to Jordanian territories in late $19^{\text {th }}$ century form another distinct minority in the Kingdom (Robins 2004: 10). There is also a considerable number of Iraqis and Syrians who left their respective countries because of the ongoing regional conflicts (Achilli 2015; Fagen 2009). Regarding faith, more than eighty percent of the Jordanian population are Sunni Muslims. The rest is formed by Christians of different denominations, mostly members of the Greek Orthodox Church. A few thousand Bahai's and Druze are present in the country as well (Central Intelligence Agency 2019).

During the time of my fieldwork in 2014, the confessional and ethnic heterogeneity of Amman's skateboarding community roughly reflected the demographics on national level. Ahmad Sahli, one of Amman's skaters, described the diverse character of the local scene in his article Skating for Self-expression published in Jordanian online magazine 7iber: "We all have a story as to why we started skateboarding, why we still skate, and why we love it. I can definitely say it's one of the most diverse scenes of Amman, and it brings people together regardless of their class, religion or nationality" (Sahli 2007). Mohammed Zakaria, seen by others as the "guru" of the skate scene is a Palestinian born in Nablus, West Bank. Saif hails from Kerak, a city in the Southern part of Jordan that is mostly inhabited by descendants of indigenous Bedouin tribes. Both Zakaria and Saif adhere to Sunni Islam. Khaled, another long-time skateboarder is a Syrian Sunni Muslim. Tamer, one of the most prolific skaters in Amman, is a Christian of Jordanian origin. Misha, a regular visitor to Share'eth Thaqafeh is half-Russian and half-Palestinian and Sufian is Circassian.

While the skate spot in Share'eth Thaqafeh was not a place where religious matters were regularly discussed, some of the skaters considered themselves devote believers. Among them was Mohammed who thoroughly observed Islamic religious practices and prayed five times a day or Saif who regularly attended Friday prayers. As Saif described, he became religious in his early twenties when he studied in the US and used to spend his free time with fellow Muslim students. At that time, he started reading the Quran and became profoundly interested in Islamic spirituality (Zakaria 2014a). Nevertheless, among members of the scene were also skateboarders who did not consider faith an important part of their identities. Misha and Sufian who spent part of their lives in Russia said that they were proselytised by both Christians and Muslims and therefore did not feel tied to either of the faiths. Tamer, on the other hand, claimed allegiance to Christianity expressed by a big cross tattooed on his shoulder. Even though he neither went to church nor observed a religious lifestyle, he perceived faith as an important part of his identity.

While confession and ethnicity differed among Jordanian skateboarders, Sahli's characterisation of the Amman skate community as "one of the most diverse scenes" becomes problematic when looking at the socioeconomic background and gender of the participants. Besides the fact that there were no female skaters at Share'eth Thaqafeh, virtually all members of the scene belonged to middle or upper-middle class. As Tamer said, there had never been "a poor skater" in Amman (Zakaria 2014b). Sahli's statement which highlights the scene's diversity thus proves to be a somewhat romanticised representation and reflects Yochim's concept of "imagined" equality. The relatively privileged status as a common characteristic of Amman's skaters resonates with El Sayed's observations from her ethnographic research among Egyptian youth. The author notices that "[...] structural inequalities, related to class position, as they intersect with urban experi- 
ences, gender identity and religion continue to play a central role in organising youth cultural experiences [...]" (El Sayed 2017: 151). One of the main reasons why skateboarding remained an activity confined to youth from higher social strata was purely material - the basic equipment necessary to pursue skateboarding was relatively costly and hardly accessible. Even though between 2009 and 2014, it was possible to buy skateboard decks from the local brand Philadelphia Skateboards in Amman, other parts of basic equipment such as polyurethane wheels and alloy trucks had to be individually shipped from abroad. As the local skaters explained, they usually relied on relatives or close friends living in Western countries to bring them skateboarding goods during their visits to Jordan. Although the equipment could be also ordered online and shipped to Jordan by delivery companies, such option was described by the skaters as too expensive. When shipping costs and customs added to the original price of the goods, sums significantly exceeded prices common in the US or Europe. While economic capital was indispensable for pursuing skateboarding, transnational ties, i.e. a form of social capital, were equally important because they allowed the skaters easier access to equipment which they needed for pursuing their activity.

The skateboarding community in Amman prior to 2014 can be characterised as a group of predominantly transnational, cosmopolitan middle or upper-middle class youth. Transnationalism, as described by Vertovec refers to maintaining ties among non-institutional groups and networks of individuals across nation-state borders (Vertovec 2009: 29). The transnational character of the scene thus refers primarily to the connection between Amman skaters, their fellow countrymen and skateboarders from other countries. However, I also deploy the term cosmopolitanism, which better serves to describe how such transnational interaction influenced processes of acculturation. According to Roudometof, while the term local denotes a defensive attitude towards an increasingly interconnected world, cosmopolitan stands for the conceptual opposite. In this understanding, cosmopolitanism is the attitude of individuals who embrace global interconnectedness and growing multiculturalism (Roudometof 2005: 121).

In the 2000's, the Amman's skate scene included several expatriates who started skateboarding in their home countries and brought their experience to Jordan, thus inspiring the local skaters. After two editions of Red Bull Local Hero Tour competition that took place in 2003 and 2005, respectively, Jordanian skaters were joined by Caleb, an American, or Bulgarian brothers Nick and Alex. The cosmopolitan character of the scene was fostered not only by frequent interaction with expatriate skateboarders, but by the fact that majority of Jordanian skaters had lived abroad themselves. This transnational experience was thus a distinct characteristic the skaters shared beyond participation in skateboarding. The most common destination where they moved either permanently or for a certain time period was the US, a country which hosts the third largest Jordanian expatriate community in the world $^{1}$ (Migration Policy Centre 2013). Hamzeh moved to the US in 2009 and subsequently enrolled in a university in New York City. As of 2014, he still resided in the US and visited Amman once to twice a year. Ahmad lived in Vermont, Jamiel lived in Indiana, and Mahdi moved to Toronto, Canada, with his parents. Saif spent a considerable part of his life in Georgia, US, and Khaled grew up in Mississippi. Anas, a skateboarder who resided in Amman at the time of my fieldwork had lived in California for more than ten years. Tamer spent one year in Washington DC with his relatives while Misha and Sufian, two skateboarders who were regularly present at Share'eth Thaqafeh in 2014, had lived in Russia. The only member of Amman's scene who never spent more than several months outside of Jordan was Mohammed, even though he had experience traveling to US and several countries around the Middle East and North Africa.

The cosmopolitan character of the scene manifested in the use of language as well. When Amman's skaters met for a session at Share'eth Thaqafeh, they often communicated in English

\footnotetext{
${ }^{1}$ The two biggest communities of Jordanian immigrants are in UAE and Saudi Arabia.
} 
instead of Arabic. Even skaters who never lived in English-speaking countries such as Misha, Sufian and Mohammed, spoke the language fluently and sometimes used it for communication with other locals. As several of Amman's skateboarders mentioned, they got accustomed to speaking English mainly because Share'eth Thaqafeh was frequently visited by foreigners who did not understand Arabic. The same explanation was given to a participant in an internet forum discussion: "Farah: 'I've always wondered why they only speak in English (at least that's what I noticed).' Mohammed: 'Well Farah, it's because as you noticed many of us come from different communities, so there's no other way of communicating except through English" (360 East 2007). Some of Amman's skaters also said that English was simply more practical for them, especially when conversations revolved specifically around skateboarding. Arabic lacks even basic "skate vocabulary" considered adequate by those who were involved in the scene and the terms used by non-skateboarders were viewed as inappropriate. To give a few examples, Arabs say le'eb skeet, which means "to play a skateboard" or they call the activity tazalluj which most commonly translates as sliding. Skateboarders are usually called mutazallijin, which is a term that also refers to roller-skaters.

The absence of specialised skateboarding terminology in Arabic and common presence of foreigners at the skate spot in Share'eth Thaqafeh provide a reasonable explanation why English became the preferred language among Jordanian skaters. However, its frequent use was also an expression of adherence to a Western youth culture and a way to identify with "global skateboarding community". As I will demonstrate in the next section, a cultural exchange between Amman's skateboarders and their foreign counterparts consisted not only of interaction with expatriate youth and occasional visitors/skaters at Share'eth Thaqafeh but also took place in the form of entrepreneurial and social projects that positioned Amman's scene in a transnational skateboarding network.

\section{Philadelphia Skateboards: Expanding a Transnational Skateboarding Network}

In the previous section, I described the transnational and cosmopolitan character of Amman's skate scene. While transnationalism was related largely to skaters' social and family backgrounds, participation in skateboarding also contributed to expanding their transnational ties as it became means to establish relationships beyond the local scene, based on shared enthusiasm for the activity. Besides interaction with expatriate youth and foreigners who occasionally came for informal visits to discover spaces for skateboarding, members of Amman's skate scene initiated or were directly involved in entrepreneurial and social projects based on active cooperation with international skate communities which also took place in digital realm. This observation resonates with Cohen's point that "[...] transnational bonds no longer have to be cemented by migration or by exclusive territorial claims. In the age of cyberspace, a diaspora can, to some degree, be held together or re-created through the mind, through cultural artefacts and through a shared imagination" (Cohen, cited in Vertovec 2009: 6). The project I will further discuss to demonstrate this point is Philadelphia Skateboards - the first transnational skateboarding brand founded by a skateboarder from Amman.

Throughout the paper, I have frequently referred to Amman's skate community as a scene. In the context of music youth cultures, the term scene commonly signifies a "space of cultural practices connecting musicians, infrastructures [...] and listeners, in a reciprocally influential fashion" (Barone 2019: 90). Similarly, a skate scene can be seen as a space formed by participants and infrastructure, which normally involves skateboarding media and industry. Even though the number of skaters in Amman never exceeded a few dozen, some members of the community felt a need to extend their skateboarding-related activities and initiate projects - i.e. create an 
infrastructure - that would contribute to the development of their scene. In 2007, Ahmad Sahli founded an online blog Skate Jordan, dedicated to photographs, videos and information related to skateboarding in Jordan which then served as the main media platform of Amman's scene before mass proliferation of social networks. The inception of what can be viewed as a local skate industry dates back to 2009, when Mohammed Zakaria established Philadelphia Skateboards as a part of his efforts to improve the availability of skateboarding hardware in Jordan. The issue was solved only partially as the brand provided solely skate decks and the rest of equipment (wheels and trucks) still had to be shipped individually to the country. Yet from the perspective of this study, Philadelphia Skateboards deserves attention for two main reasons. Firstly, it is a curious example of an interplay between local and global as it merged aspects of a global youth culture - skateboarding - with distinctively local aesthetics to emphasise the Arab origin of the brand. Whereas "Philadelphia" refers to the ancient name of Jordanian capital, meaning "brotherly love", the graphic designs on the boards accentuated the brand's relation to the Arab culture and drew inspiration from commonly held stereotypes about Arabs. The first series of Philadelphia products included a board with a drawing of men wearing kuffiyat - traditional headscarves, a board depicting a donkey, accompanied by the quote "My camel's in the garage", or a board with an image of a bomb, saying "Philadelphia is the bomb". The imagery referred to preconceived ideas of the Arab world as overtly traditionalist, backwards or a hotbed of terrorism. The authors of the graphics - Zakaria and several Jordanian designers - sought to point at the contrast between oversimplified representations of the Arab world expressed by the images and actual complexity of Arab societies in which youth re-appropriate creative ways of self-expression, thus challenging stereotypes widespread in the West (Zakaria 2014). Such youthful creativity was manifested by the very objects on which the images were placed - the skateboards.

Secondly, Philadelphia represents a unique case of an entrepreneurial project that emerged from the core of Amman's skate scene and subsequently became means for building a transnational community formed by skateboarders from the MENA region and beyond. Since the establishment of the brand, Zakaria sought to expand his business network - not only to increase the sales of the products, but also to strengthen active interaction with skaters from different countries. Thus, Philadelphia Skateboards can be seen as a platform based on mutual enthusiasm for skateboarding, or transnational affect. As Wise and Velayuthm notice, affect has been increasingly recognised not only as an individual psychological state, but also an intersubjective and therefore cultural and social matter. In the increasingly interconnected world, we can argue that "[...] the circulation of affect and emotion in transnational social fields augments and mediates the viability of long-distance relationships across national borders [...]" (Wise, Velayutham 2017: 117) and that such processes are at the core of shaping youth cultural networks.

Between 2009 and 2013, Philadelphia Skateboards were sold in Jordan, Lebanon, United Arab Emirates, Morocco and Belgium. Likewise, Zakaria set up an international team of skaters who promoted the brand, chiefly through social and niche media, in exchange for Philadelphia products. The first rider on Philadelphia team was Maysam Faraj, a Syrian living in Dubai, followed by Jordanian skater Saif al-Qaisi who had pursued his studies in the US and later moved to Lebanon. In the following years, the team included a Dutch skater Tristan Koelewijn, Canadian Marcus Marcoux, and American Evan Collison. The selection of team riders was not arbitrary, as all of them had previously got to know Zakaria in person. Saif was Zakaria's long-time friend, since they grew up together in Amman and regularly met at Sharea't Thaqafeh. Marcus, Evan and Maysam lived in UAE and met Zakaria during their travels. They were all members of an informal group "Yalla Yakhi", established as a platform to connect skateboarders in the Middle East, both in virtual and physical space (Marcoux 2014). Maysam and Marcus met Zakaria during skateboarding trips to Amman in 2007 and 2009, respectively. Evan made friends with 
the founder of Philadelphia personally two years later, when they both travelled to Tunisia as members of a team that worked on a documentary about the growth of local youth cultures after Jasmine Revolution. Tristan, who also participated in the Tunisian tour, met Zakaria for the first time when he visited Amman with a group of other skateboarders from Benelux.

The map of Philadelphia distribution network, as well as the composition of the team shows that the brand was an international, collaborative enterprise. It served as a platform to stimulate an active interaction and expand ties between individual skaters and communities in the region and beyond. Due to the brand's emphasis on its Arab origin, skaters across the MENA region who followed its social media accounts approved of Philadelphia as a project that represented their scenes and raised awareness about skateboarding in the Arab world among both Arab and Western audiences. This was, for instance, the case of Soufiane Elalami, a Moroccan skater who set up Philadelphia distribution in his country after he discovered the brand via Facebook. Even though the founder of the brand and Elalami never met in person, Philadelphia became known among Moroccan skaters due to the existence of the distribution. The brand's presence in Morocco stimulated interaction between the Moroccan and Jordanian scenes on social media, creating a network based on transnational affect wherein skaters from the respective countries exchanged information, photographs or videos related to skateboarding (Elalami 2017).

Besides playing a role in strengthening a network of Arab and Western skaters on platforms such as Facebook and Instagram, the existence of the brand contributed to real-life interaction between skaters from different countries as well. Philadelphia team members occasionally visited Jordan to personally meet the brand's founder or film and take skateboarding photographs at Amman's skate spots. On their visits, the skaters from UAE, US or Europe shared experience and developed ties with members of the local skate community during mutual sessions at Share'eth Thaqafeh and other spaces in the city. As several of Amman's skaters explained, the fact that the existence of Philadelphia allowed for easier access to equipment was beneficial for the scene. However, what they deemed as equally important was its role in representing their community and making it a part of a larger transnational network.

\section{Hills Skatepark: Skateboarding as a Means of Social Inclusion}

The idea that skateboarding can serve as means to bring together people from diverse communities was also one of the central motives behind 7Hills Skatepark, a project conducted in Amman by the NGO Make Life Skate Life (MLSL). In 2014, the organisation constructed a public skatepark in Amman with the aim to provide vulnerable youth with access to sport infrastructure and safe public space, thus bringing skateboarding in Amman to a whole new context. From a subcultural practice in unsanctioned urban spaces pursued by a group of Westernized young males, it gradually evolved into a tool for inclusion and empowerment of underprivileged youth and children, both male and female.

The 7Hills Skatepark project is a part of a broader phenomenon of charitable endeavours, generally known as Action Sports for Peace and Development (ASDP) which employ action sports to empower youth predominantly in developing countries (Thorpe, Rinehart 2012). Alongside organisations such as Skateistan or SkatePal, MLSL falls into a growing number of skateboarding social movements that "[...] are founded by action sport participants who use preexisting structures and connections within and across local, national, and global sporting cultures and industries to raise awareness and fundraise for issues they deem to be socially significant" (Thorpe, Rinehart 2012: 116). According to the origin story, the organisation was established after Arne Hillerns and two other skaters from Germany traveled to Bangalore, India, where they encountered a small skateboarding community. These local skateboarders were keen to create their own 
space for riding but lacked the necessary experience to do so. The German group then offered to provide their know-how and assist with the construction of India's first skatepark (Hillerns 2014; Make Life Skate Life 2019). Since the German skaters previously engaged in construction of several skateparks in Europe - most notably Zweier, a well-known DIY skateboarding space in Hannover - they developed the indispensable skills and, furthermore, an extensive social network which included experienced skatepark builders from several European countries (Confusion Magazine 2013). Thus, they were able to mobilise a group of volunteers which then traveled to Bangalore and played an essential role in successful realisation of the skatepark.

The success in India led Hillerns to establish the organisation Make Life Skate Life. In projects that followed, the new NGO elaborated on the scheme of using preexisting connections within transnational DIY community and working closely with nascent local skate scenes; rather than implementing skateboarding in locations where the activity was previously non-existent, the organisation sought to partner with local skate communities whose members could consequently become skateboarding pioneers in their respective countries. Following this pattern in Jordan, the organisation established contacts with members of the local skate scene in the first phase of the project. Subsequently, Mohammed Zakaria - Jordanian skateboarding "guru" and founder of Philadelphia Skateboards - took on the role of local manager of the project, while several other of Amman's skaters joined the construction works as volunteers.

To a large extent, the fact that close collaborations with nascent local skateboarding scenes became one of the core principles of MLSL in their projects was determined by the lasting positive impact this scheme had shown to have on the development of skateboarding in India. After the skatepark build in Bangalore, a local group of skateboarders led by Abhishek Belmar used their experience not only to foster a community in their own city, but also to construct other similar spaces across India (Tammas 2019). However, the success of the Bangalore skatepark may have been the primary reason why MLSL subsequently tended to overestimate the ability of small skateboarding groups in various developing countries to fulfil the organisation's vision of building inclusive communities around the practice of skateboarding at new MLSL skateparks. While in India, the Bangalore project was a crucial incentive for a growth of vibrant skateboarding scene, this was not necessarily the case in other locations. In an interview for Free Skate Magazine, Amber Edmondson provides an account of her experience volunteering as a skateboarding tutor at one of the MLSL skateparks in Sulaymaniyah, Iraq, in which she points at some of the shortcomings in the organisation's policies. Edmondson mentions that while the skatepark was presented as finished and open to the public, it was, in fact, not in a safe condition to be used by local youth and children. Moreover, a lack of systematic effort on the part of the NGO to develop a sustainable program focused on education and community-building caused that the skatepark did not serve its desired purpose. As Edmondson put it: "I don't think that anyone should be building anything unless they're willing to either commit six months themselves or they have an agreement with a partner organisation that is going to stay and do skate programming for six months" (Edmondson 2019).

Looking at the circumstances of the 7Hills Skatepark construction in light of the Sulaymaniyah project, we can identify some key issues that hindered the transformation of the skatepark into a site for implementing "[...] skate programs that aim to include females, disadvantaged and refugee youth, and use skateboarding as a tool for teaching cross-cultural communication, creative self expression and resilience to underserved youth populations" (Make Life Skate Life, 2020). Firstly, it was the over-reliance on local skateboarders' ability to become community-leaders and fulfil the organisation's visions. To put such scheme into practice requires a set of educational, and organisational skills, knowledge and commitment which may not have been necessarily present within the small group of Amman's skateboarders. Moreover, there was a lack of material re- 
sources. Even though a few dozen loaner skateboards were provided by MLSL volunteers to be used by the local youth and children after 7Hills Skatepark was opened, no funding was secured that would allow for setting up a mid-term or long-term skateboarding education program - envisioned to be organised by Amman skaters in cooperation with local NGOs. While Mohammed Zakaria was actively involved in 7Hills Skatepark project from its inception, he simply lacked the time to organise a regular program at the skatepark on his own since he had to focus on paid work. Other skaters, in Zakaria's words, did not have the commitment or experience needed for such task and the existing skate scene was therefore not able to take on the role expected by MLSL (Zakaria 2017).

As I will show later, organised activities at 7Hills Skatepark started in 2016, when Belgian skateboarder Kas Wauters embarked on implementing a new educational program. However, in the first two years of the skatepark's existence, the well-intended effort of MLSL and the international group of volunteers put into the skatepark construction was to little avail since the space did not serve the initial purpose. As Wauters recalled: "When I first came to Amman in 2016, I saw the park mostly empty or there were street kids fighting and throwing stones" (Wauters 2019). While this might be attributed to a lack of experience in securing a long-term, sustainable program on the part of MLSL and over-reliance on the capacity of local skaters, we can also seek a more complex explanation. What must be taken into account here are the neoliberal conditions in which small ASDP organisations such as MLSL operate and which determine how these subjects gain resources for their activities. Generally, ASDP organisations have several options of funding their projects - these include sponsorships from companies, fundraising campaigns and grants from various international or state institutions. Whereas the first two MLSL projects - skateparks in Bangalore, India and La Paz, Bolivia - relied on a multinational clothing company sponsorship, 7Hills Skatepark was financed via crowdfunding campaign, in which donors contributed a total amount of 20,000 USD (7Hills 2019). Indeed, such option of financing a philanthropic project is seemingly more independent than relying on a single corporate sponsor. However, as Thorpe and Rinehart point out, NGOs reliant on individual donations need to look for marketing strategies to attract potential donors in a saturated mediascape which inevitably shapes their policies. "To survive, and indeed thrive, in an environment with increasingly scarce financial resources and limited emotional capacities, NGOs are embracing new media technologies, and drawing inspiration from the marketing strategies of for-profit organisations" (Thorpe and Rinehart 2012). Since MLSL established itself as an organisation which primarily builds skateparks around the world, it was subsequently expected to fulfil such role by the audiences representing potential donors. With the limited amount of human and financial resources, the organisation is then likely to prioritise constructing a new skatepark at the expense of investing in long-term programs which would ensure that their existing projects have lasting impact. Even though, according to MLSL official website, "[...] the goal is that our local partners take full ownership and independently run the projects in the long-term [...]" it is not necessarily provided that they "[...] acquire enough skills to lead their next projects". (Make Life Skate Life 2019). While the website listed nine finished skatepark projects as of 2019, the actual impact of these projects varied considerably in respective locations. As I described above, neither 7Hills Skatepark in Amman, Jordan nor Suli Skatepark in Sulaymaniyah, Iraq served the intended purpose in the first years of their existence. According to Finn, one of the volunteers who participated in the construction of Pokhara Skatepark in Nepal in 2017, a similar scenario could be observed in case of this MLSL project as well. "The local communities were provided some loaner boards, but that wasn't enough. They are too preoccupied with securing the basic needs for living to focus on skateboarding" (Finn 2019).

This critique should not imply that MLSL leadership lack self-reflexivity and do not seek to improve their existing projects. Rather, what I suggest is integrating an active approach to secure 
programming at the newly-built skateparks as an indispensable part of the organisation's projects. While 7Hills Skatepark eventually became a space serving its originally intended function, the shift was initiated and managed by an external actor. As I previously mentioned, regularly organised activities in Amman's 7Hills Skatepark were renewed in late 2016, primarily due to the effort of Kas Wauters. As a skateboarder and education graduate, Wauters was looking for an opportunity to volunteer in a non-Western country as a skateboarding teacher and therefore reached out to several skateboarding NGOs. After learning from the director of MLSL that 7Hills Skatepark was not currently serving its intended purpose, Wauters decided to move to Amman and attempt to restart an educational program at the skatepark. With the help of Mohammed Zakaria, Wauters approached several NGOs such as Sawiyan which led to the establishment of weekly skateboarding classes for children and youth from Sudanese, Iraqi and Syrian communities. The organisation also partnered with community leadership at a Palestinian refugee camp in the city of Jerash and started to organise classes for local children, providing transportation from the camp to the skatepark. In cooperation with Reclaim Childhood - an NGO which specialises in sports education for young females - 7Hills set up a weekly skate class devoted primarily to girls (Wauters 2019). As Wauters explained, the aim of the 7Hills organisation was to empower youth and children through a creative physical activity and, at the same time, to work towards overcoming social and racial divisions by creating "a melting pot" for different communities (Wauters 2019).

In their quest for giving youth opportunities for self-development and stimulating positive social change, many ASDP organisations face the uneasy task of providing aid while avoiding the pitfalls of cultural imperialism. The new 7Hills organisation formed in 2016 focused on developing a long-term educational program which inevitably raises questions whether the policies of the NGO take into account desires and sensibilities of the addressed communities. According to 7Hills website, skateboarding classes and loaner program reach approximately 150 youth and children on a weekly basis. Around $70 \%$ of the participants come from refugee communities while females represent roughly $40 \%$. As the organisation states, their goal is to reach equal male and female participation (7Hills 2019). The focus on fostering gender equality in 7Hills programming can be seen as a part of a broader global phenomenon of the so-called "Girl Effect". In the context of ASDP organisations, Thorpe, Hayhurst and Chawansky note how women in developing countries have been increasingly portrayed as empowered actors with their own agency. This "positive" imagery, as the authors suggest, is problematic in that it obfuscates deeper structural inequalities between empowered girls and women in the Global North and their counterparts in the Global South (Thorpe, Hayhurst, Chawansky 2018: 304) Likewise, the over-emphasis on female empowerment may not be sufficiently reflective of cultural norms in certain geographical locations (Thorpe, Hayhurts, Chawansky 2018: 317). Nevertheless, 7Hills organisation has shown a rather good understanding and reflexivity regarding these issues in order to make their programming sustainable. While the NGO encourages increase of female participation in their program, girls and young women interested in learning skateboarding through 7Hills program can either attend mixed sessions (classes where both genders come to skateboard) or classes designed solely for females. Moreover, even though these classes have been led by male instructors, in 2019, 7Hills started training older and more experienced female participants so they could teach other girls as well (Wauters 2019).

Another aspect which has also proven to be crucial in building a viable ASDP project is an active inclusion of the addressed communities' members in decision-making positions. While local skateboarder Mohammed Zakaria was co-running the project since the inception, the organisation has also taken steps to engage the most committed and experienced participants from the skateboarding classes to a youth leadership program. Within the program, several young males who regularly attended 7Hills Skatepark took on the position of skateboarding instructors. As Wauters 
explained, these young males - together with several girls who were training to become instructors - were expected to take over the leadership of the organisation. Even though, as Wauters admitted, the expected scenario may not succeed if the youth either decide to pursue careers that will not allow them to commit enough time to 7Hills organisation or move out of Jordan, he saw handing the leadership over to local youth as the best way to sustain the project. According to Wauters, the pursuit of this new skateboarding group still materially depends on 7Hills, yet their immersion in skate culture exceeds participation in activities run by the organisation. Besides skating at the park, they also go for regular street skateboarding sessions to unsanctioned spaces, exploring a broader potential for creative self-expression that the activity offers (Wauters 2014). Following the footsteps of skaters who were frequenting Share'eth Thaqafeh since the early 2000 's, they have gradually taken on the role of new skateboarding pioneers in the city. Thus, a new scene has emerged with the potential to continue in cultivating a local skate culture. A skate culture that is shaped by the experience of growing up as a disadvantaged young person in Amman and, at the same time, informed by the values of social inclusion, equality and diversity which the 7Hills' organisation attempts to promote through its activities.

\section{Conclusion}

Studying a skateboarding scene on a periphery is most relevant in relation to broader global trends that influence the development of youth cultures in general and skate culture in particular. In this paper, I have shown that proliferation of the internet played an essential role in the emergence of the first skateboarding community in Amman as it allowed skateboarding enthusiasts to connect on chat forums and draw inspiration from online skate media. As I have noted, the evolution of Amman's skate scene was also encouraged by competitions organised by Red Bull company which stimulated an active interaction among several groups of skaters in the city. From a wider perspective, the role of Red Bull illustrates global involvement of multi-national corporations in skateboarding, continuously growing since the mid 1990's. What should be pointed out as well is the relation between skateboarding and the emergence of social media which has contributed to the increase of trans-local interaction between skaters and scenes from different countries. In the case of the Jordanian skate scene, I have specifically shown how using social media helped Mohammed Zakaria to promote his brand Philadelphia Skateboards and connect with an international audience.

Confronting these global developments with regional and local social, political, economic and cultural particularities then allows us to render an accurate portrayal of skate culture as a constantly evolving intersection between local and global. I have explained that until 2014, skateboarding in Amman was an activity pursued by a group of Westernised youth. However, this pattern changed profoundly with the foundation of 7Hills Skatepark which included young males and females from underprivileged strata. On one hand, studying this project lets us explore another significant trend in global skateboarding - i.e. using the activity as means to provide disadvantaged communities with an outlet for physical activity and creative self-expression. On the other hand, it gives us an opportunity to understand the nature of a regional refugee crisis which was one of the central motives behind conducting the project. Elaborating on the interplay between global manifestations of skateboarding culture and such socio-political realities is now becoming an increasingly topical subject of scholarly research. More so as social movements and charitable organisations - such as Make Life Skate Life - are getting more professionalized and substantially change the circumstances of the development of skateboarding in various locations across the developing world and - more broadly - the patterns of globalisation of youth cultures. 


\section{Bibliography}

Achilli, L. 2015. "Syrian Refugees in Jordan: a Reality Check." Migration Policy Centre, Policy Briefs 2: 1-12, https://doi.org/10.2870/821248.

Atencio, M., B. Beal, E. M. Wright, Z. McClain. 2018. Moving Boarders: Skateboarding and the Changing Landscape of Urban Youth Sports. Fayetteville: The University of Arkansas Press, https:// doi.org/10.2307/j.ctv7vcss3.

Barone, S. 2019. "Feeling so Hood: Rap, Lifestyles and the Neighborhood Imaginary in Tunisia." British Journal of Middle Eastern Studies 46 (1): 88-103, https://doi.org/10.1080/13530194.2017.1371001.

Beal, B., L. Weidman. 2003. Authenticity in the Skateboarding World. Linfield College Faculty Publications.

Bennet, A. 1999. "Subcultures or Neo-Tribes? Rethinking the Relationship Between Youth, Style and Musical Taste." Sociology 33 (3): 599-617, https://doi.org/10.1017/S0038038599000371.

Borden, I. 2001. Skateboarding, Space and the City: Architecture and the Body. Oxford: Berg Publishers.

Castaneda, A. 2008. "Kick Flipped: How Skateboarding Rides With Race" [online] Spark Action, 31. 10. 2008 [cit. 21. 4. 2019]. Available from: https://sparkaction.org/content/kick-flipped-how-skateboardingrides-race.

Central Intelligence Agency. 2019. "Middle East: Jordan." [online] CIA World Factbook [cit. 15. 4. 2019]. Available from: https://www.cia.gov/library/publications/the-world-factbook/geos/jo.html.

Dupont, T. 2014. "From Core to Consumer: The Informal Hierarchy of the Skateboard Scene." Journal of Contemporary Ethnography 43 (5): 556-581, https://doi.org/10.1177/0891241613513033.

El Sayed, H. 2017. "Mediated Imagination, Class and Cairo's Young Cosmopolitans." Pp 152-176 in T. Sabry, L. Ftouni (eds.). Arab Subcultures: Transformations in Theory and Practice. London: I. B. Tauris, https://doi.org/10.5040/9781350985339.ch-006.

Elalami, S. 2017. Personal communication. March 10, 2017.

Fagen, P. W. 2009. "Iraqi Refugees: Seeking Stability in Jordan." CIRS Occasional Papers 1, https:// doi.org/10.2139/ssrn.2825853.

Hall, S., T. Jefferson (eds.). 1976. Resistance Through Rituals: Youth Subcultures in Post-war Britain. Birmingham: The Centre for Contemporary Cultural Studies.

Hillerns, A. 2014. Personal communication. September 30, 2014.

Hebdige, D. 1979. Subculture: The Meaning of Style. London: Methuen \& Co Ltd.

Jensen, S. Q. 2018. "Towards a neo-Birminghamian conception of subculture? History, challenges, and future potentials." Journal of Youth Studies 21 (4): 405-421, https://doi.org/10.1080/ 13676261.2017.1382684.

Kehily, M. J., A. Nayak. 2008. "Global Femininities: consumption, culture and the significance of place." Discourse: Studies in the Cultural Politics of Education 29 (3): 325-342, https://doi.org/10.1080/ 01596300802259103.

Lorr, M. J. 2016. "Skateboarding as a Technology of the Collective." Pp 139-151 in K-J. Lombard (ed.). Skateboarding: Subcultures, Sites and Shifts. New York: Routledge.

Make Life Skate Life. 2020. "About us." [online] Make Life Skate Life, nedatováno [cit. 30. 3. 2020]. Available from: https://makelifeskatelife.org/about-us.

Marcoux, M. 2014. Personal communication. November 15, 2014.

Migration Policy Center. 2013. "Migration Facts Jordan." [online] Migration Policy Center [cit. 15. 4. 2019]. Available from: http://www.migrationpolicycentre.eu/docs/fact_sheets/Factsheet\%20Jordan.pdf.

Nick, I. 2013. "The Epic Build: Holystoked - Bangalore DIY, India." [online] Confusion International Skateboard Magazine, 13. 3. 2013 [cit. 15. 2. 2015]. Available from: http://www.confuzine.com/tag/bangalor/.

Nilan. P., C. Feixa (eds.). 2006. Global Youth: Hybrid Identities, Plural Worlds. London: Routledge, https://doi.org/10.4324/9780203030523.

Ritzer, G. 1983. "The McDonaldization of Society." Journal of American Culture 6 (1): 100-107, https:// doi.org/10.1111/j.1542-734X.1983.0601_100.x.

Robins, P. 2004. A History of Jordan. Cambridge: Cambridge University Press.

Roudometof, V. 2005. "Transnationalism, Cosmopolitanism and Glocalization." Current Sociology 53 (1): 113-135, https://doi.org/10.1177/0011392105048291.

Sabry, T., L. Ftouni (eds.). 2017. Arab Subcultures: Transformations in Theory and Practice. London: I. B. Tauris, https://doi.org/10.5040/9781350985339. 
Sahli, A. 2007. "The beginning." [online] Skate Jordan, 13. 12. 2007 [cit. 15. 4. 2019]. Available from: http://skatejordan.blogspot.com/2007/12/beginning.html.

Sahli, A. 2008. "Shmeisani blacklist." [online] Skate Jordan, 2. 7. 2008 [cit. 15. 4. 2019]. Available from: http://skatejordan.blogspot.com/2008/07/shmeisani-blacklist.html.

Schiller, N. G., L. Basch, C. Blanc-Szanton. 1992. "Towards a Definition of Transnationalism: Introductory Remarks and Research Questions." Pp ix-xiv in N. G. Schiller (ed.). Transnationalism: A New Analytic Framework for Understanding Migration. New York: New York Academy of Science, https://doi.org/10.1111/j.1749-6632.1992.tb33482.x.

Tammas, O. 2019. "India's Skate Revolution: An Interview with Atita and Abhishek." [online] Skateism, 3. 7. 2019 [cit. 25. 3. 2020]. Available from: https://www.skateism.com/indias-skate-revolution-aninterview-with-atita-and-abhishek/.

Thorpe, H., N. Ahmad. 2015. "Youth, action sports and political agency in the Middle East: Lessons from a grassroots parkour group in Gaza." International Review for the Sociology of Sport 50 (6): 678-704, https://doi.org/10.1177/1012690213490521.

Thorpe, H., L. M. C. Hayhurst, M. Chawansky. 2018. "The Girl Effect and 'Positive' Repesentations of Sporting Girls of the Global South: Social Media Portrayals of Afghan Girls on Skateboards." Pp 299323 in K. Tofolleti, H. Thorpe, J. Francombe-Webb (eds.). New Sporting Femininities: Embodied Politics in Postfeminist Times. Cham: Palgrave Macmillan, https://doi.org/10.1007/978-3-319-72481-2_14.

Thorpe, H., R. Rinehart 2012. "Action Sport NGOs in a Neoliberal Context: The Cases of Skateistan and Surf-Aid International." Journal of Sport and Social Issues 37 (2): 115-141, https://doi.org/10.1177/ 0193723512455923.

Vertovec, S. 2009. Transnationalism: Key Ideas. Abingdon: Routledge, https://doi.org/10.4324/ 9780203927083.

Yochim, E. CH. 2010. Skate Life: Re-Imagining White Masculinity. Ann Arbor: University of Michigan Press, https://doi.org/10.2307/j.ctv65sw5s.

Wauters, K. 2019. Personal communication. May 10, 2019.

Zahran, M. 2012. "Jordan is Palestinian." Middle East Quarterly 19 (1): 3-12.

Zakaria, M. 2014a. Personal communication. November 5, 2014.

Zakaria, M. 2014b. Personal communication. November 10, 2014.

Zakaria, M. 2014c. Personal communication. October 15, 2014.

360 East. 2007. "Who is Amman's best skateboarder?" [online] 360 East, 13. 10. 2007 [cit. 15. 2. 2015]. Available from: http://www.360east.com/?p=860.

7Hills Skatepark. 2019. [online] Facebook [cit. 20. 4. 2019]. Available from: https://www.facebook.com/ 7HillsPark/.

\section{About author}

Jakub Novotný is a Ph.D. candidate at the Department of Anthropology, University of West Bohemia. In his research, he focuses on the youth culture of skateboarding in countries of the Middle East and North Africa. Recently, he has conducted ethnographic fieldwork in Morocco, where he primarily studied the developments of skateboarding scene in the context of growing state support and institutionalization of urban sports. 